\title{
European experience with the Mosaic bioprosthesis
}

\author{
Walter Benno Eichinger, MD \\ Florian Botzenhardt ${ }^{\mathrm{a}}$ \\ Ralf Gunzinger, $M D^{\mathrm{a}}$ \\ Bernhard M. Kemkes, MDa \\ Andrzej Sosnowski, MD ${ }^{\mathrm{b}}$ \\ Dominique Maïza, $\mathrm{MD}^{\mathrm{c}}$ \\ Eduardo Otero Coto, $\mathrm{MD}^{\mathrm{d}}$ \\ Niels Bleese, MD
}

From Krankenhaus München Bogenhausen, München, Germany ; Glenfield General Hospital, Leicester, United Kingdom $^{\text {b; }}$ CHR Cote De Nacre, Caen, France ${ }^{\mathrm{c}}$; Clinico Universitario, Valencia, Spain ${ }^{\mathrm{d}}$, and Albertinen Krankenhaus, Hamburg, Germany.

Medtronic, Inc (Minneapolis, Minn), provided financial support to the listed departments to defray research expenses.

Received for publication Sept 6, 2001; revisions requested Nov 20, 2001; revisions received Dec 14, 2001; accepted for publication Dec 18, 2001.

Address for reprints: Walter B. Eichinger, MD, Deutsches Herzzentrum München, Department of Cardiovascular Surgery, Lazarettstrasse 36, D-80636, München, Germany (E-mail: eichinger@dhm.mhn.de).

J Thorac Cardiovasc Surg 2002;124:333-9

Copyright $(\odot) 2002$ by The American Association for Thoracic Surgery

0022-5223/2002 $\$ 35.00+0 \quad \mathbf{1 2 / 1 / 1 2 2 5 5 2}$

doi:10.1067/mtc.2002.122552
Objective: The purpose of this study was to prospectively evaluate the clinical and hemodynamic performance of the Mosaic bioprosthesis (Medtronic, Inc, Minneapolis, Minn).

Methods: The stented porcine bioprosthesis combines the amino-oleic acid antimineralization treatment and the zero-pressure differential fixation technique for improved tissue durability. From February 1994 to May 1999, a total of 561 patients underwent valve replacement with the Mosaic bioprosthesis at 5 centers in Europe: 461 in the aortic and 100 in the mitral position. There were 261 women and 300 men; mean age at implantation was 70 years (range, 23-89 years). Mean follow-up was 2.9 years (range, 0-6.2 years), with a total follow-up of 1710.1 patient-years.

Results: Postoperative mortality was $4.2 \%$ per patient-year, including a valverelated mortality of $0.4 \%$ per patient-year. The freedom from event rates in the aortic position at 5 years and in the mitral position at 4 years were, respectively, $96.6 \% \pm 1.1 \%$ and $94.9 \% \pm 3.3 \%$ for primary thromboembolism, $96.4 \% \pm 5.0 \%$ and $87.1 \% \pm 4.8 \%$ for antithromboembolic-related hemorrhage, $99.1 \% \pm 0.5 \%$ and $100 \%$ for thrombosed prosthesis, $98.8 \% \pm 1.2 \%$ and $100 \%$ for structural valve deterioration, $98.8 \% \pm 0.7 \%$ and $100 \%$ for nonstructural dysfunction, $98.4 \% \pm$ $0.6 \%$ and $94.4 \% \pm 3.8 \%$ for endocarditis, and $95.4 \% \pm 1.6 \%$ and $95.3 \% \pm 3.7 \%$ for explant and reoperation. Mean pressure gradient values at 5 years ranged from 7.5 to $15.9 \mathrm{~mm} \mathrm{Hg}$ in the aortic position and at 4 years from 2.0 to $6.9 \mathrm{~mm} \mathrm{Hg}$ in the mitral position across all valve sizes.

Conclusions: Clinical and hemodynamic performance of the Mosaic bioprosthesis were very satisfactory during the first 6 years after clinical introduction.

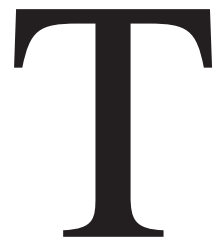

he Mosaic bioprosthesis (Medtronic Inc, Minneapolis, Minn) is a porcine heart valve with a low-profile stent fixed with glutaraldehyde combining zero-pressure and root-pressure techniques and treated with $\alpha$-amino-oleic acid (AOA) to reduce tissue calcification. This European multicenter study was intended to evaluate the hemodynamic and clinical performance of the Mosaic valve in the aortic and mitral positions within the first 6 years after clinical introduction in 1994.

\section{Patients and Methods}

This prospective, nonrandomized, multicenter clinical trial of the Mosaic bioprosthesis began in February 1994. Patients given a diagnosis of valvular heart disease who required replacement of their aortic or mitral heart valve were eligible to enter the study. Patients undergoing concomitant procedures and those having active endocarditis at the time of implantation were entered into the study. Patients who required concomitant valve replacement or who already had a preexisting prosthetic valve in another position were excluded from enrollment. The study was 
TABLE 1. Preoperative and operative data

\begin{tabular}{|c|c|c|c|c|}
\hline \multirow[b]{2}{*}{ Variable } & \multicolumn{2}{|c|}{ Aortic } & \multicolumn{2}{|c|}{ Mitral } \\
\hline & $\%$ & $\mathbf{N}$ & $\%$ & $\mathbf{N}$ \\
\hline \multicolumn{5}{|l|}{ Age at implantation (y) } \\
\hline Mean & 70 & & 69 & \\
\hline Range & $23-89$ & & $41-84$ & \\
\hline$\leq 60$ & 13.0 & 60 & 15.0 & 15 \\
\hline $61-70$ & 29.1 & 134 & 38.0 & 38 \\
\hline $71-80$ & 52.5 & 242 & 44.0 & 44 \\
\hline$>80$ & 5.4 & 25 & 3.0 & 3 \\
\hline \multicolumn{5}{|l|}{ Sex } \\
\hline Male & 58.1 & 268 & 32 & 32 \\
\hline Female & 41.9 & 193 & 68 & 68 \\
\hline \multicolumn{5}{|l|}{ NYHA classification } \\
\hline Class I & 0.9 & 4 & 0.0 & 0 \\
\hline Class II & 20.2 & 93 & 19.0 & 19 \\
\hline Class III & 66.2 & 305 & 58.0 & 58 \\
\hline Class IV & 12.8 & 59 & 23.0 & 23 \\
\hline \multicolumn{5}{|l|}{ Aortic valve lesion } \\
\hline Stenosis & 61.4 & 283 & 16.0 & 16 \\
\hline Insufficiency & 13.4 & 62 & 59.0 & 59 \\
\hline Mixed & 25.2 & 116 & 25.0 & 25 \\
\hline \multicolumn{5}{|l|}{ Valve size } \\
\hline $19 \mathrm{~mm}$ & 1.3 & 6 & NA & NA \\
\hline $21 \mathrm{~mm}$ & 26.2 & 121 & NA & NA \\
\hline $23 \mathrm{~mm}$ & 38.2 & 176 & NA & NA \\
\hline $25 \mathrm{~mm}$ & 28.0 & 129 & 9.0 & 9 \\
\hline $27 \mathrm{~mm}$ & 5.4 & 25 & 25.0 & 25 \\
\hline $29 \mathrm{~mm}$ & 0.9 & 4 & 43.0 & 43 \\
\hline $31 \mathrm{~mm}$ & NA & NA & 22.0 & 22 \\
\hline $33 \mathrm{~mm}$ & NA & NA & 1.0 & 1 \\
\hline \multicolumn{5}{|l|}{ Concomitant procedures } \\
\hline None & 47.5 & 219 & 64.0 & 64 \\
\hline$C A B G^{*}$ & 35.1 & 162 & 24.0 & 24 \\
\hline Other & 17.4 & 80 & 12.0 & 12 \\
\hline Variable & Mean \pm SD & $\mathbf{N}$ & Mean \pm SD & $\mathbf{N}$ \\
\hline \multicolumn{5}{|l|}{ Aortic crossclamp time (min) } \\
\hline All patients & $77.1 \pm 29.8$ & 461 & $76.4 \pm 28.7$ & 100 \\
\hline Isolated procedure & $60.5 \pm 17.8$ & 227 & $68.5 \pm 25.8$ & 64 \\
\hline Concomitant procedures & $93.4 \pm 30.3$ & 233 & $89.8 \pm 28.7$ & 36 \\
\hline
\end{tabular}

$C A B G$, Coronary artery bypass grafts; $N A$, not available.

approved by the respective institutional ethics committees, and all patients gave informed consent to participate. The study was supported by Medtronic, Inc, the manufacturer of the Mosaic bioprosthesis.

Until May 2000, a total of 461 patients (268 male and 193 female patients) underwent isolated aortic valve replacement (AVR) and 100 patients (32 male and 68 female patients) underwent isolated mitral valve replacement (MVR) with the Mosaic bioprosthesis. The age at implantation ranged from 23 to 89 years (mean, 70 years) in the aortic group and from 41 to 84 years (mean, 69 years) in the mitral group. Table 1 summarizes the preoperative and operative data.

Valve replacement was undertaken by means of standard cardiopulmonary bypass at mild hypothermia with cold crystalloid cardioplegia. When the size of the bioprosthesis is being assessed, it is important to use the manufacturer-supplied Mosaic sizer. Because of the possibility of the so-called Supra-x placement, the specific construction of the Mosaic sizer and of the bioprosthesis often allow the implantation of a one-size-larger valve compared with the conventional supra-annular placement. This makes a significant increase in the effective flow orifice possible, as mentioned previously. ${ }^{1}$

The clinical follow-up was done during the initial hospitalization for valve replacement, 6 months after the operation, and at annual intervals. The examination included a hematologic check and a hemodynamic assessment by means of transthoracic echocardiography. Mean systolic pressure gradients were calculated with the modified Bernoulli equation. Effective orifice areas were calculated with the continuity equation:

$$
\begin{aligned}
& \mathrm{AVR}=\left[\left(\mathrm{LVOT}_{\text {Diameter }}^{2} \times 0.785 \times \mathrm{TVI}_{\mathrm{LVOT}}\right) / \mathrm{TVI}_{\text {Aortic Valve }}\right] \\
& \text { and } \\
& \mathrm{MVR}=\left[\left(\mathrm{LVOT}_{\text {Diameter }}^{2} \times 0.785 \times \mathrm{TVI}_{\mathrm{LVOT}}\right) / \mathrm{TVI}_{\text {Mitral Valve }}\right]
\end{aligned}
$$


TABLE 2. Echocardiographic data

\begin{tabular}{|c|c|c|c|c|c|c|c|c|}
\hline \multirow[b]{3}{*}{ Valve size } & \multicolumn{4}{|c|}{ Mean pressure gradient $(\mathrm{mm} \mathrm{Hg})^{*}$} & \multicolumn{4}{|c|}{ Effective orifice area $\left(\mathrm{cm}^{2}\right)$} \\
\hline & \multicolumn{2}{|c|}{ Early follow-upt } & \multicolumn{2}{|c|}{ 5-y follow-up } & \multicolumn{2}{|c|}{ Early follow-upt } & \multicolumn{2}{|c|}{ 5-y follow-up } \\
\hline & $\mathbf{N}$ & Mean \pm SD & $\mathbf{N}$ & Mean \pm SD & $\mathbf{N}$ & Mean \pm SD & $\mathbf{N}$ & Mean \pm SD \\
\hline \multicolumn{9}{|l|}{ Aortic } \\
\hline $19 \mathrm{~mm}$ & 6 & $21.6 \pm 6.3$ & $4 \ddagger$ & $15.9 \pm 5.0 \ddagger$ & 6 & $1.2 \pm 0.2$ & $4 \ddagger$ & $1.2 \pm 0.1 \ddagger$ \\
\hline $21 \mathrm{~mm}$ & 115 & $15.1 \pm 6.8$ & 17 & $15.2 \pm 4.9$ & 115 & $1.5 \pm 0.5$ & 17 & $1.6 \pm 0.3$ \\
\hline $23 \mathrm{~mm}$ & 172 & $12.7 \pm 5.0$ & 22 & $12.8 \pm 5.7$ & 172 & $1.9 \pm 0.5$ & 22 & $1.8 \pm 0.3$ \\
\hline $25 \mathrm{~mm}$ & 120 & $11.4 \pm 4.4$ & 10 & $9.5 \pm 2.4$ & 120 & $2.1 \pm 0.6$ & 10 & $2.3 \pm 0.5$ \\
\hline $27 \mathrm{~mm}$ & 24 & $10.3 \pm 4.0$ & 2 & $10.4 \pm 0.3$ & 24 & $2.5 \pm 0.7$ & 2 & $2.6 \pm 0.6$ \\
\hline $29 \mathrm{~mm}$ & 3 & $18.8 \pm 6.4$ & 1 & 7.5 & 3 & $2.0 \pm 0.6$ & 1 & 3.0 \\
\hline \multirow[t]{2}{*}{ All sizes } & 440 & $13.0 \pm 5.7$ & 52 & $12.8 \pm 5.2$ & 440 & $1.9 \pm 0.6$ & 52 & $1.7 \pm 0.5$ \\
\hline & \multicolumn{2}{|c|}{ Early follow-upt } & \multicolumn{2}{|c|}{ 4-y follow-up } & \multicolumn{2}{|c|}{ Early follow-upt } & \multicolumn{2}{|c|}{ 4-y follow-up } \\
\hline \multicolumn{9}{|l|}{ Mitral } \\
\hline $25 \mathrm{~mm}$ & 9 & $6.5 \pm 3.2$ & 2 & $4.6 \pm 1.9$ & 9 & $1.8 \pm 0.5$ & 2 & $2.6 \pm 0.6$ \\
\hline 27 mm & 24 & $4.7 \pm 1.7$ & 4 & $3.8 \pm 0.7$ & 21 & $1.9 \pm 0.8$ & 3 & $1.5 \pm 0.3$ \\
\hline $29 \mathrm{~mm}$ & 43 & $4.2 \pm 1.6$ & 9 & $4.4 \pm 1.6$ & 34 & $1.9 \pm 0.5$ & 6 & $1.8 \pm 0.6$ \\
\hline $31 \mathrm{~mm}$ & 22 & $4.9 \pm 1.3$ & 3 & $2.7 \pm 0.7$ & 20 & $1.6 \pm 0.5$ & 3 & $2.1 \pm 0.3$ \\
\hline 33 mm & 1 & 6.0 & 1 & 6.0 & 1 & 2.5 & 1 & 1.8 \\
\hline All sizes & 99 & $4.7 \pm 1.8$ & 19 & $4.1 \pm 1.4$ & 85 & $1.8 \pm 0.6$ & 15 & $1.9 \pm 0.5$ \\
\hline
\end{tabular}

${ }^{*}$ Aortic: mean systolic gradient; Mitral: mean diastolic gradient.

tBefore hospital discharge or 30 days or less after the operation.

$\ddagger 0$ ne-year result because $19 \mathrm{~mm}$ was not followed up later.

with LVOT defined as left ventricular outflow tract and TVI defined as time velocity integral.

Prosthetic insufficiency was graded on the basis of color Doppler assessment as mild, moderate, or severe. The echocardiographic examination has been documented in detail previously. ${ }^{2}$

In the aortic group $3.7 \%(\mathrm{n}=17)$ and in the mitral group $2.0 \%$ of the patients $(\mathrm{n}=2)$ were lost to follow-up. The mean follow-up was 3.2 years (range, $0-6.2$ years) in the aortic and 2.6 years (range, 0-6.1 years) in the mitral position. The total follow-up included 1453.9 patient-years in the aortic group and 256.2 patient-years in the mitral group, respectively.

The guidelines of the Society of Thoracic Surgeons and The American Association of Thoracic Surgeons were followed for the reporting of mortality and valve-related morbidity. ${ }^{3}$ Linearized complication rates were calculated by dividing the number of events by the sum of patient-years expressed as a percentage. Survival analyses with the Kaplan-Meier product-limit method were used to estimate survival and the freedom from valve-related adverse events.

\section{Results}

\section{Hemodynamic Evaluation}

In Table 2 the echocardiographically obtained mean pressure gradients and effective orifice areas of the different valve sizes are depicted.

Postoperative echocardiographic examination revealed prosthetic regurgitation in $7.6 \%$ of the patients after AVR (34/449, 31 mild and 3 moderate) and in 4.0\% (4/100, all mild) of the patients after MVR. The regurgitation was transvalvular in 11 (all mild), paravalvular in 17 (15 mild and 2 moderate), and indeterminate (ie, not assessable by the echocardiographer) in 6 (5 mild and 1 moderate) patients in the aortic group and transvalvular and paravalvular each in 2 patients in the mitral group. Six years after implantation of the Mosaic bioprosthesis, $11.1 \%(2 / 18,1$ mild and 1 moderate, both transvalvular) of the aortic patient group and no patients in the mitral group showed prosthetic insufficiency.

\section{Prosthetic Valve-Related Adverse Events}

The actuarial rates of freedom from prosthetic valve-related adverse events and the linearized frequencies are shown in Table 3.

\section{Mortality}

The early mortality (ie, $<30$ days after the operation), if the patient was discharged from the hospital or at any time after implantation if the patient was not discharged from the hospital, was $2.4 \%$ for the aortic group and $1.0 \%$ for the mitral group. The late mortality (ie, $>30$ days after the operation), if the patient was discharged from the hospital, was $11.8 \%$ with a linearized rate of $3.7 \%$ per patient-year in the aortic group (on the basis of 1416.6 late patient-years) and $9.1 \%$ with a linearized rate of $3.6 \%$ per patient-year in the mitral group (on the basis of 248.1 late patient-years), respectively, including valve-related mortality of $0.5 \%$ per patient-year in the aortic group $(\mathrm{n}=7)$ and $0.4 \%$ per patient-year in the mitral group $(n=1)$.

The Kaplan-Meier survival functions after AVR and MVR with the Mosaic bioprosthesis are depicted in Figure 1. 
TABLE 3. Freedom from prosthetic valve-related adverse events

\begin{tabular}{|c|c|c|c|c|c|c|c|c|}
\hline \multirow[b]{2}{*}{ Adverse event } & \multirow[b]{2}{*}{ Position } & \multicolumn{2}{|c|}{ Early Events* } & \multicolumn{2}{|c|}{ Late Eventst } & \multicolumn{3}{|c|}{ Actuarial freedom from event $(\% \pm \mathrm{SE})$} \\
\hline & & $\mathbf{N}$ & $\% /$ patients & $\mathbf{N}$ & $\% /$ patient-yearł & $1 \mathrm{y}$ & $3 y$ & $4 / 5$ y§ \\
\hline \multirow[t]{2}{*}{ Thromboembolism } & Aortic & 3 & 0.7 & 8 & 0.6 & $98.7 \pm 0.5$ & $97.8 \pm 0.7$ & $96.6 \pm 1.1$ \\
\hline & Mitral & 1 & 1.0 & 2 & 0.8 & $98.0 \pm 1.6$ & $98.0 \pm 2.5$ & $94.9 \pm 3.3$ \\
\hline \multirow[t]{2}{*}{ Valve thrombosis } & Aortic & 0 & 0.0 & 4 & 0.3 & $99.6 \pm 0.3$ & $99.0 \pm 0.5$ & $99.0 \pm 0.5$ \\
\hline & Mitral & 0 & 0.0 & 0 & 0.0 & $100 \pm 0.0$ & $100 \pm 0.0$ & $100 \pm 0.0$ \\
\hline \multirow[t]{2}{*}{ Structural valve deterioration } & Aortic & 0 & 0.0 & 1 & 0.1 & $100 \pm 0.0$ & $100 \pm 0.0$ & $98.8 \pm 1.2$ \\
\hline & Mitral & 0 & 0.0 & 0 & 0.0 & $100 \pm 0.0$ & $100 \pm 0.0$ & $100 \pm 0.0$ \\
\hline \multirow[t]{2}{*}{ Nonstructural valve dysfunction } & Aortic & 0 & 0.0 & 4 & 0.3 & $99.3 \pm 0.4$ & $99.3 \pm 0.4$ & $98.8 \pm 0.7$ \\
\hline & Mitral & 0 & 0.0 & 0 & 0.0 & $100 \pm 0.0$ & $100 \pm 0.0$ & $100 \pm 0.0$ \\
\hline \multirow[t]{2}{*}{ Primary paravalvular leak } & Aortic & 2 & 0.4 & 4 & 0.3 & $98.9 \pm 0.5$ & $98.6 \pm 0.6$ & $98.6 \pm 0.6$ \\
\hline & Mitral & 0 & 0.0 & 0 & 0.0 & $100 \pm 0.0$ & $100 \pm 0.0$ & $100 \pm 0.0$ \\
\hline \multirow[t]{2}{*}{ Endocarditis } & Aortic & 0 & 0.0 & 6 & 0.4 & $99.5 \pm 0.3$ & $98.4 \pm 0.6$ & $98.4 \pm 0.6$ \\
\hline & Mitral & 1 & 1.0 & 2 & 0.8 & $99.0 \pm 1.4$ & $99.0 \pm 1.4$ & $94.4 \pm 3.8$ \\
\hline \multirow{2}{*}{$\begin{array}{l}\text { Antithromboembolic-related } \\
\text { hemorrhage }\end{array}$} & Aortic & 8 & 1.7 & 11 & 0.8 & $96.4 \pm 0.9$ & $96.4 \pm 0.9$ & $96.4 \pm 0.9$ \\
\hline & Mitral & 4 & 4.0 & 5 & 2.0 & $93.0 \pm 2.6$ & $90.7 \pm 3.4$ & $87.1 \pm 4.8$ \\
\hline \multirow[t]{2}{*}{ Reoperation/explant } & Aortic & 0 & 0.0 & 12 & 0.8 & $98.6 \pm 0.6$ & $97.7 \pm 0.8$ & $95.4 \pm 1.6$ \\
\hline & Mitral & 0 & 0.0 & 2 & 0.8 & $98.9 \pm 1.1$ & $98.9 \pm 1.1$ & $95.3 \pm 3.7$ \\
\hline
\end{tabular}

*Less than 30 days after the operation.

tGreater than 30 days after the operation.

‡Calculations are based on 1416.6 (aortic) and 248.1 (mitral) late patient-years.

$\S$ Five-year results of aortic position and 4-year results of mitral position.

\section{Clinical Improvement}

Before implantation of the Mosaic bioprosthesis, $79.0 \%$ of the patients with aortic valve lesions and $81.0 \%$ of those with mitral valve lesions were classified in New York Heart Association (NYHA) classes III and IV. Six months after the operation $98.4 \%$ in the aortic group and $94.7 \%$ in the mitral group were classified in NYHA classes I and II; 6 years after the operation $100 \%$ of the patients in both groups were so classified. Comparing preoperative state and results of the 1-year evaluation, $91.0 \%$ of the patients in the aortic group and $83.0 \%$ of those in the mitral group had an improvement in NYHA classification.

\section{Discussion}

The Mosaic bioprosthesis is a stented porcine heart valve designed to minimize the biomodal failure mechanisms of bioprostheses, mechanical wear, and chemically induced intrinsic mineralization by means of the combination of several technologies. It is fitted to a low-profile acetal polymer stent, which is covered with polyester fabric. The prosthetic tissue is treated with glutaraldehyde to minimize the consequences of antigenicity after porcine valve implantation. ${ }^{4}$ The fixation of the Mosaic bioprosthesis is a combination of the so-called zero-pressure and root-pressure methods: equal pressure is applied to the inflow and outflow ends of the valve. By this method, the aortic root is pressurized to maximize the flow area, and no pressure is exerted on the leaflets. The natural shape generally is preserved, and the disadvantages of low- and high-pressure fixation (ie, the changed arrangement of collagen and elastic fibers in the porcine leaflets that leads to altered tissue extensibility and pliability) can be reduced.5,6 The bioprosthetic tissue is treated with AOA to mitigate chemical calcification. AOA is strongly bound to the tissue by forming Schiff base covalent linkages with aldehydes remaining from the fixation with glutaraldehyde. Chen and associates ${ }^{7}$ and Duarte and coworkers ${ }^{8}$ proved the effective retardation of calcium ion diffusion into the tissue by means of AOA. Long-term results will show whether the anticalcific competence of the treatment with AOA is effective.

\section{Aortic Position}

The mean systolic pressure gradients are very low (ie, 7.5 to $15.9 \mathrm{~mm} \mathrm{Hg}$ across all sizes). Comparing these results with those with other established stented bioprostheses, the Mosaic performance is equivalent to that of the Hancock modified orifice II bioprosthesis ${ }^{2}$ (Medtronic) and the Carpentier-Edwards pericardial valve (Edwards Lifesciences, Irvine, Calif), ${ }^{9}$ with the larger sizes (27 and $29 \mathrm{~mm}$ ) showing excellent hemodynamic function. Our results corresponded to the data published by Thomson and colleagues ${ }^{10}$ and Wong and associates ${ }^{11}$ in other Mosaic studies. Because the construction and implantation of stentless bioprostheses comprise a different technique, a direct comparison of the hemodynamic performance would be flawed. However, generally these Mosaic results approach the results obtained with stentless devices: Yun and coworkers ${ }^{12}$ reported mean systolic pressure gradients of the Freestyle bioprosthesis of $6.7 \pm 3.4 \mathrm{~mm} \mathrm{Hg}(21 \mathrm{~mm}), 2.9 \pm 2.3 \mathrm{~mm} \mathrm{Hg}(23 \mathrm{~mm})$, $3.7 \pm 2.6 \mathrm{~mm} \mathrm{Hg}(25 \mathrm{~mm})$, and $6.0 \pm 4.2 \mathrm{~mm} \mathrm{Hg}(27 \mathrm{~mm})$ after 4 years, and Westaby and associates ${ }^{13}$ showed Freestyle results 6 months after the operation of $9.2 \pm 3.3 \mathrm{~mm}$ 

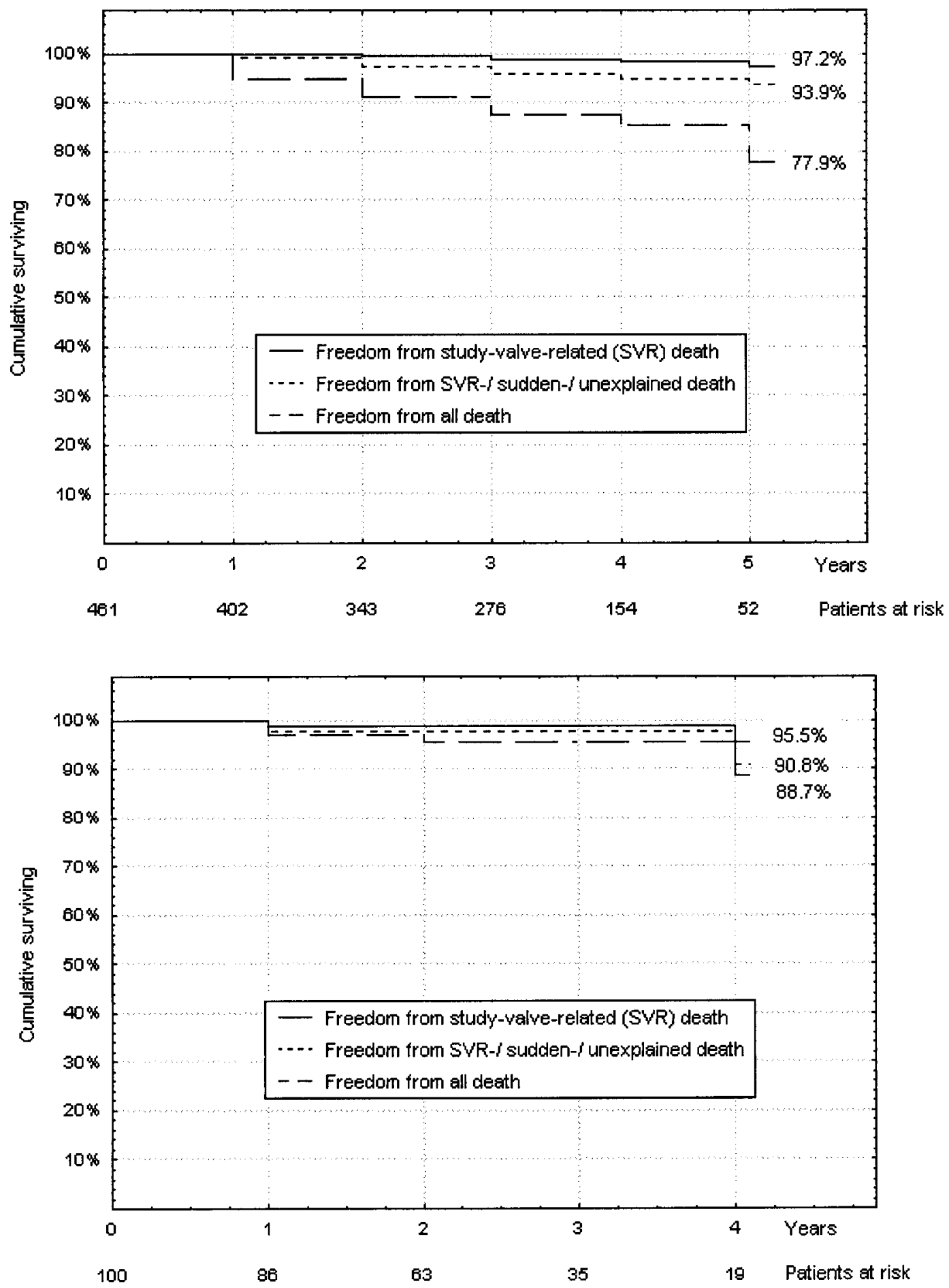

Figure 1. Survival function: Top, After AVR; bottom, after MVR.

$\mathrm{Hg}(21 \mathrm{~mm}), 5.2 \pm 2.3 \mathrm{~mm} \mathrm{Hg}(23 \mathrm{~mm}), 4.3 \pm 2.0 \mathrm{~mm} \mathrm{Hg}$ $(25 \mathrm{~mm})$, and $4.0 \pm 1.9 \mathrm{~mm} \mathrm{Hg}(27 \mathrm{~mm})$. Mohr and coworkers ${ }^{14}$ described mean systolic pressure gradients of the Toronto SPV bioprosthesis (St Jude Medical, Inc, St Paul, Minn) of $11.1 \mathrm{~mm} \mathrm{Hg}$ (21 mm and $23 \mathrm{~mm}), 8.4 \mathrm{~mm}$
$\mathrm{Hg}$ (25 mm), $8.9 \mathrm{~mm} \mathrm{Hg}(27 \mathrm{~mm})$, and $7.7 \mathrm{~mm} \mathrm{Hg}(29 \mathrm{~mm})$ 1 week after the operation.

The effective orifice areas of the Mosaic bioprosthesis after 5 years (1.6-3.0 $\mathrm{cm}^{2}$ across all sizes) are also very satisfactory. Our results corresponded to the measurements 
obtained during other Mosaic studies. ${ }^{11,15}$ They exceed the results of Hancock modified orifice II, ${ }^{2}$ Carpentier-Edwards Perimount, ${ }^{9}$ and Medtronic Intact. ${ }^{16}$ Again, under consideration of the different conditions of stented and stentless bioprostheses, the $23-\mathrm{mm}\left(2.16 \pm 0.65 \mathrm{~cm}^{2}\right), 25-\mathrm{mm}$ $\left(2.38 \pm 1.17 \mathrm{~cm}^{2}\right)$, and $27-\mathrm{mm}\left(2.70 \pm 0.73 \mathrm{~cm}^{2}\right)$ Freestyle valves in the series of Yun and colleagues ${ }^{12} 4$ years after the operation exceeded our Mosaic results, whereas the Freestyle study of Dumesnil and coworkers ${ }^{15} 1$ year after the operation revealed lower effective orifice areas in comparison with these Mosaic results $\left(21 \mathrm{~mm}, 1.35 \pm 0.21 \mathrm{~cm}^{2} ; 23\right.$ $\mathrm{mm}, 1.48 \pm 0.33 \mathrm{~cm}^{2} ; 25 \mathrm{~mm}, 2.00 \pm 0.39 \mathrm{~cm}^{2} ; 27 \mathrm{~mm}$, $\left.2.32 \pm 0.48 \mathrm{~cm}^{2}\right)$.

As a limitation of the hemodynamic comparisons, it has to be stated that the sizes of the bioprostheses were taken over by the definitions given by each manufacturer. The fact that the manufacturers have chosen to size their prostheses in different ways can complicate the comparisons of pressure gradients and effective orifice areas because a $23-\mathrm{mm}$ prosthesis of one manufacturer's type may not fit the same anulus as a $23-\mathrm{mm}$ prosthesis from another manufacturer. This complication should be minimized in further studies by grouping the valves according to the intraoperative measured anulus instead of the manufacturer's description. In this study the measurements are also referred to the manufacturer's valve size and not to the patients' anulus. The actuarial freedom rates from valve-related adverse events after 5 years are satisfactory. The low incidence of structural valve deterioration, endocarditis, thromboembolism, and nonstructural valve dysfunction was especially convincing. The causes of valve-related death were antithromboembolism-related hemorrhage, valve thrombosis, reoperation for valve thrombosis (the patient died of multiorgan failure 2 days after reoperation), and reoperation for structural valve deterioration each in 1 patient and cerebrovascular attack in 3 patients. The cause of the relatively high rate of antithromboembolism-related hemorrhage (freedom after 5 years, $96.4 \% \pm 0.9 \%$; linearized rate, $0.8 \%$ per patient-year) might be found in the high quota of patients in the aortic group receiving anticoagulants throughout the 6 postoperative years $(61.5 \%$ in the 5 -year follow-up). The majority $(50.7 \%)$ took acetylsalicylic acid $(100 \mathrm{mg} / \mathrm{d})$, which was indicated because of coronary artery disease. Some patients $(10.8 \%)$ constantly received warfarin for reasons like atrial fibrillation and left atrial and ventricular dilation and dysfunction. There certainly were some patients taking warfarin without any reasonable indication but because of missing information from the general practitioner about the need for anticoagulation in patients with heart valve bioprostheses. Combinations of different types of anticoagulants (warfarin, heparin, acetylsalicylic acid, and ticlid) were seen in $14.6 \%$ of all patients only during the early postoperative period. The freedom rates from reoperation and explanta- tion of the Mosaic bioprosthesis $(95.4 \% \pm 1.6 \%$ after 5 years; linearized rate, $0.8 \%$ per patient-year) are average results when compared with those of other bioprostheses. The reason for reoperation was primary valve thrombosis in 4 patients, endocarditis in 4 patients, primary paravalvular leak in 2 patients, and nonstructural valve dysfunction and structural valve deterioration each in 1 patient.

\section{Mitral Position}

The hemodynamic performance of the Mosaic bioprosthesis in the mitral position is satisfactory. The mean diastolic pressure gradients after 4 years ranged from 2.7 to $6.0 \mathrm{~mm}$ $\mathrm{Hg}$ across all sizes. Lemieux and associates ${ }^{16}$ reported pressure gradients of the Intact valve in the mitral position 1 year after the operation of $6.18 \pm 2.60 \mathrm{~mm} \mathrm{Hg}(25 \mathrm{~mm})$, $5.04 \pm 1.86 \mathrm{~mm} \mathrm{Hg}(27 \mathrm{~mm}), 4.69 \pm 1.73 \mathrm{~mm} \mathrm{Hg}(29$ $\mathrm{mm})$, and $3.28 \pm 0.67 \mathrm{~mm} \mathrm{Hg}(31 \mathrm{~mm})$. The CarpentierEdwards pericardial valve showed pressure gradients of 4.1 $\mathrm{mm} \mathrm{Hg}(27 \mathrm{~mm})$ and $3.0 \mathrm{~mm} \mathrm{Hg}(29-33 \mathrm{~mm})$ in a 10-year series by Aupart and colleagues. ${ }^{17}$ The effective orifice areas of the Mosaic bioprostheses in the mitral position are quite small (1.5-2.6 $\mathrm{cm}^{2}$ across all sizes at 4 years) compared with those of other biologic valves. The Intact valve showed effective orifice areas of $1.85 \pm 0.43 \mathrm{~cm}^{2}(25 \mathrm{~mm})$, $1.93 \pm 0.39 \mathrm{~cm}^{2}(27 \mathrm{~mm}), 2.33 \pm 0.39 \mathrm{~cm}^{2}(29 \mathrm{~mm})$, and $2.10 \pm 0.26 \mathrm{~cm}^{2}(31 \mathrm{~mm}) 1$ year after the operation. ${ }^{16}$ Aupart and coworkers ${ }^{17}$ described effective orifice areas of $2.6 \mathrm{~cm}^{2}(27 \mathrm{~mm}), 2.7 \mathrm{~cm}^{2}(29 \mathrm{~mm}), 2.6 \mathrm{~cm}^{2}(31 \mathrm{~mm})$, and $3.1 \mathrm{~cm}^{2}(33 \mathrm{~mm})$ for the Carpentier-Edwards pericardial valve. There is no obvious explanation for the small Mosaic effective orifice areas in the mitral position, and thus this finding should be critically observed in future studies. The actuarial freedom rates from valve-related adverse events in the mitral position 4 years after implantation show good results: there were no incidences of structural valve deterioration and nonstructural valve dysfunction and a low rate of thromboembolism and valve-related death. Causes of valve-related death were antithromboembolic-related hemorrhage and permanent neurologic event, each in 1 patient. Endocarditis was present in 2 patients, resulting in a low rate of freedom of $94.4 \% \pm 3.8 \%$ after 4 years. Because the second incidence occurred during the fourth postoperative year with only 19 patients included in the 4-year follow-up period, the method of Kaplan-Meier estimates, which is based on the number of patients at risk, might have contributed to the unsatisfactory result. The same cause might underlie the relatively low freedom from reoperation and explantation $(95.3 \% \pm 3.7 \%$ after 4 years $)$ because the 2 valves affected by endocarditis caused the only 2 reoperations and explantations. The relatively low freedom from antithromboembolism-related hemorrhage might be attributed to the high rate of patients in the mitral group receiving anticoagulants postoperatively: $82.5 \%$ in the 4-year follow-up period $56.5 \%$ for warfarin, $17.4 \%$ for acetylsali- 
cylic acid, $4.3 \%$ for ticlid, and $4.3 \%$ for warfarin and acetylsalicylic acid). Coronary artery disease was the main indication for acetylsalicylic acid $(100 \mathrm{mg} / \mathrm{d})$ and ticlid. Left atrial and ventricular enlargement and atrial fibrillation as results of the mitral lesion were the indications for warfarin. Again, the missing knowledge of the general practitioner about the thrombogenicity of bioprostheses might attribute to the high rate of constant warfarin recipients.

\section{Conclusion}

In conclusion, the Mosaic bioprosthesis, both in the aortic and in the mitral position, showed very good hemodynamic performance in comparison with that of other stented bioprostheses. Compared with other biologic valves, the freedom from prosthetic valve-related adverse events was very satisfactory. Further investigation and data collection will be necessary to determine long-term results and to decide on the device's inferiority or superiority compared with that of established heart valve devices.

\section{References}

1. Eichinger WB, Guenzinger R, Botzenhardt F, Simmerl D, Gansera B, Kemkes BM. The Mosaic bioprosthesis in the aortic position at five years. J Heart Valve Dis. 2000;9:653-60.

2. Eichinger WB, Schütz A, Simmerl D, Gansera B, Breuer M, Haslinger $\mathrm{B}$, et al. The Mosaic bioprosthesis in the aortic position: hemodynamic performance after 2 years. Ann Thorac Surg. 1998;66:S126-9.

3. Edmunds LH, Clark RE, Cohn LH, Grunkemeier GL, Miller CM, Weisel RD. Guidelines for reporting morbidity and mortality after cardiac valvular operations. Ann Thorac Surg. 1996;62:932-5.

4. Carpentier A, Lemaigre G, Robert L, Carpentier S, Dubost C. Biological factors affecting long-term results of valvular heterografts. J Thorac Cardiovasc Surg. 1969;58:467-83.
5. Vesley I. Analysis of the Medtronic Intact bioprosthesis valve. Effects of "zero-pressure" fixation. J Thorac Cardiovasc Surg. 1991;101: 90-9.

6. Vesley I, Lozon A, Talman E. Is zero-pressure fixation of bioprosthetic valves truly stress free? J Thorac Cardiovasc Surg. 1993;106: 288-98.

7. Chen W, Schoen FJ, Levy RJ. Mechanism of efficacy of 2-amino oleic acid for inhibition of calcification of glutaraldehyde-pretreated porcine bioprosthetic heart valves. Circulation. 1994;90:323-9.

8. Duarte IG, MacDonald M J, Cooper WA. In vivo hemodynamic, histologic and antimineralization characteristics of the Mosaic bioprosthesis. Ann Thorac Surg. 2001;71:92-9.

9. Aupart MR, Neville P, Dreyfus X, Meurisse Y, Sirinelli A, Marchand M. The Carpentier-Edwards pericardial aortic valve: intermediate results in 420 patients. Eur J Cardiothorac Surg. 1994;8:277-80.

10. Thomson D, Jamieson WRE, Dumesnil J, Busse E, Peniston C, Mbtras $\mathrm{J}$, et al. Medtronic Mosaic porcine bioprosthesis satisfactory early clinical performance. Ann Thorac Surg. 1998;66:122-5

11. Wong SP, Legget ME, Greaves SC, Barratt-Boyes BG, Milsom FP, Raudkivi PJ. Early experience with the Mosaic bioprosthesis: a new generation porcine valve. Ann Thorac Surg. 2000;69:1846-50.

12. Yun KL, Sintek CF, Fletcher AD, Pfeifer TA, Kochamba GS, Hyde $\mathrm{MR}$, et al. Aortic valve replacement with the Freestyle stentless bioprosthesis: five-year experience. Circulation. 1999;100(suppl):II$17-23$.

13. Westaby S, Amarasena N, Long V, Prothero A, Amarasena GA, Banning AP, et al. Time-related hemodynamic changes after aortic replacement with the Freestyle stentless xenograft. Ann Thorac Surg. 1995;60:1633-8.

14. Mohr FW, Walther T, Baryalei M, Falk V, Autschbach R, Scheidt A, et al. The Toronto SPV bioprosthesis: one-year results in 100 patients. Ann Thorac Surg. 1995;60:171-5.

15. Dumesnil J, LeBlanc MH, Cartier P, Métras J, Desaulniers D, Doyle $\mathrm{D}$, et al. Hemodynamic features of the Freestyle aortic bioprosthesis compared with stented bioprosthesis. Ann Thorac Surg. 1998;66: S130-3.

16. Lemieux MD, Jamieson WRE, Landymore RW, Dumesnil JG, Metras J, Munro Al, et al. Medtronic Intact porcine bioprosthesis: Clinical performance to seven years. Ann Thorac Surg. 1995;60:258-63.

17. Aupart MR, Neville PH, Hammami S, Sirinelli AL, Meurisse YA, Marchand MA. Carpentier-Edwards pericardial valves in the mitral position: ten-year follow-up. J Thorac Cardiovasc Surg. 1997;113: 492-8. 